\title{
COVID-19 Pandemic and Hygiene: Assessment of Running-water Infrastructure in Secondary Schools in Ijebu North Local Government Area, Ogun State, Nigeria
}

\author{
Olajuyigbe A. O., Okubena M. R., Rotowa O. O.* and Ayodele O. A. \\ Department of Urban and Regional Planning, Federal University of Technology, Akure, Nigeria \\ Corresponding Author: *oorotowa@futa.edu.ng
}

https://doi.org/10.36263/nijest.2021.02.0296

\begin{abstract}
COVID-19 is an infectious disease, a product of a freshly discovered coronavirus. With no specific cure as of now, preventing its spread is important to minimize its outbreak. The study was carried out on secondary schools in Ijebu-North Local Government Area (LGA), one of the 20 LGAs in Ogun State, Nigeria. Primary data on water availability, supply, connection to buildings, handwashing facility coverage and functionality were sourced from public secondary schools in Ijebu-North LGA with the aid of questionnaires. Findings revealed that only one school (Molusi College, Ijebu-Igbo) is fully equipped with running water connected to buildings and with functional handwashing facilities in place. Most of the schools do not have water infrastructure that can support adequate hygiene, with a score of 16 out of the total 95 available scores. Since regular and thorough washing of hands with soap and water, reduces the chances of being infected by or spreading COVID-19, this study advocates for direct taking over of water infrastructure provided in schools by the Water Agency in the areas where these schools are allocated. This takeover will be for the purpose of routine maintenance for the sustainability of the water infrastructure. Government and other donors should facilitate investments in water, sanitation and hygiene in order to prepare these schools for resumption and sustenance after the health crisis.
\end{abstract}

Keywords: COVID-19 Pandemic, Running Water Infrastructure, Secondary School

\subsection{Introduction}

History has shown that infectious diseases have wreaked havoc among societies, cities and countries of the world. Several infectious diseases had emerged and re-emerging in new and strange deadly forms. In the past, over twenty epidemics and plagues had ravaged different parts of the world with some of them declared as global pandemic. Owens (2020) reported that history of plagues and epidemics dated the pre-historic period from the Circa Disease of $3000 \mathrm{BC}$ to the recent Ebola and Zika Viruses of the 21st century with about four of them (Flu Pandemic: 1889-1890, Asian Flu: 19571958, AIDS Pandemic: 1981 till date, and H1N1 Swine Flu: 2009-2010) declared as pandemic. The world is now battling another global pandemic; Coronavirus disease (COVID-19), a new microbe enemy causing significant ill health and death, with no known cure at present (WHO, 2020a).

COVID-19 is an infectious disease, a product of a freshly discovered coronavirus. Its symptoms when contracted include mild, moderate or severe respiratory illness, which can lead to death in some cases (WHO, 2020a). Update as at August $10^{\text {th }}, 2020$ shows that the world has 20,380,437 confirmed cases of COVID-19 and sadly with about 743,013 deaths (WHO, 2020b). In Nigeria and Ogun State, the study area, update shows 47, 157 confirmed cases, 955 deaths and 1,478 cases, 24 deaths respectively (NCDC, 2020). With no specific cure for the disease as of now, preventing its spread is important to minimize the outbreak's impact on loss of lives, public health, economy and general livelihood including the continuous spread of civilization. According to the Water Aid Report (2020), one of the most potent ways to minimize the spread of infectious diseases, including COVID-19 is through handwashing with soap and running-water. The World Health Organization Report (2020c) asserted 
that "hand" has a crucial role to play in the transmission of COVID-19 because of the fact that the causative agent SARS-COV-2 primarily spreads through touching of its droplets and contacts further transmits them by touching surfaces, sensitive body parts or other people. It is thus necessary that everyone, especially public stakeholders, provides the necessary water infrastructure to allow hand hygiene in public places (Water Aid, 2020) which include schools. There is no gain saying the fact that many households and public places still lack improved water facilities for proper use and hygiene. According to the report of UNICEF and WHO (2019), 40\% of the global population still lack basic handwashing facilities with soap and water available. This amounts to about 3 billion people, out of which 1.6 billion had limited facilities lacking soap or water and 1.4 billion had no facility at all. It is alarming to discover that nearly three quarter of the population of the least developed countries lacked handwashing facilities with soap and water and five out of eight SDG regions representing about $52 \%$ of the global population do not even have data on hygiene (UNICEF and WHO, 2019).

Meanwhile, for about 2 decades now, humanity has been experiencing coronavirus-related diseases, for example, Ebola and SARS which have caused serious illness in the past and posed challenges to the public health sector. It is however sad that few lessons were learnt from these misfortunes as most public facilities including schools still lacked infrastructures and measures to contain outbreak of diseases. SARS-COV-2, the culprit agent for Coronavirus disease is the current misfortune of the World and the world apex body declared it as a public health emergency in January 2020 and eventually a pandemic in March of the same year (Balkhair, 2020). Currently, schools and other public places were under lockdown and the world is in search of ways out of these doldrums. Schools are envisaging resumption and one of the conditions of the possibility of this is hygiene at its best. Water is a pre-requisite for hygiene and running-water in particular is among the necessary provisions to curb the spread of COVID-19. To what extent are the schools equipped and how best are they prepared for resumption? It is from this perspective that this study is conceived to assess the availability and condition of running-water infrastructure and facilities in secondary schools of IjebuNorth local government area of Ogun State. This will determine the situation of water in the schools; assess the rate of functionality of the water infrastructure and evaluate the level of preparedness of the educational institutions towards helping to flatten the curve of the COVID-19 pandemic in the area and beyond for the purpose of saving lives of the young ones when schools resume.

\subsection{Nexus of water, hygiene and health}

Literature has revealed that not having access to water and sanitation facilities leads to a number of health consequences. In many cases, these consequences affect not only those directly lacking access but the impact often spread much further. For clarity of purpose, UNDP (2006) revealed that there is strong correlation between adequate and improved water supply and improved health. Lack of adequate water according to the UNDP leads to great health risks.

Tornquist (2007) noted that, there are numerous diseases connected to insufficient and unsafe water supply. She explained that microorganism in human excreta can contaminate drinking water due to inadequate sanitation arising from inadequate water supply, whereas other diseases caused by bacteria or parasites can also originate from lack of access to water for hygienic purposes. Pascale (2009) grouped the consequences of lack of or inadequacy of good water supply under: health consequences; livelihood consequences; and environmental consequences. He elucidates that, in order to prevent dehydration and diseases, every person needs a minimum level of water a day. This ranges between 15-50 litres per person per day. He then asserted that many diseases emerging in developing countries are in one way or another closely related to water and sanitation and represent the biggest health threat for people living in these countries. Every year, approximately 3.4 million people die due to waterborne diseases, with the greatest health burden falling on children (Pascale, 2009).

Olajuyigbe and Fasakin (2010) expressed the worries of UN (2002); UNEP (2002) and WHO/UNICEF (2004) that, despite the importance of water, a global paucity of safe drinking water is still been witnessed. This, according to them has the consequences of a large proportion of human being resorting to the use of potentially harmful sources of water. The implications of which are dimmed prospects for the billions of people locked in a cycle of poverty and diseases. Similarly, Flanagan et al. (2012) reported that millions of people are exposed to dangerous levels of biological 
contaminants and chemical pollutants in their drinking water due to inadequate management of urban, industrial or agricultural wastewater. They explained that, dangerous high concentrations of chemical hazards, such as arsenic and fluoride, originating from natural sources affect millions and cause diseases such as cancer and fluorosis. Inorganic arsenic is present at high levels in some ground water in greater concentration than the WHO value of $10 \mu \mathrm{g} / \mathrm{L}$ and this will require multi-disciplinary approach to safe drinking water procurement to avoid diseases in such areas (Flanagan et al., 2012).

More comprehensively, the World Health Organization WHO (2012) estimates that in 2008, diarrhea diseases claimed the lives of 2.5 million people and this burden is greater than the combined burdened of HIV/AIDS and malaria for children under the age of five. The body reported a total of 58 countries from all continents having a cumulative of 589,854 cases of cholera in 2011, representing an increase of $85 \%$ over and above that of 2010 . The greatest proportions of these cases were reported from the Island of Hispaniola and the African continent (WHO, 2012).

Ajibade et al. (2015) did an analysis of the water sources, usage of water and sanitary issues in Nigeria and reported that about $48 \%$ of Nigerians make use of surface water for their domestic needs. They noted that, this number of people may be potentially at the risk of epidemic outbreak if our surface waters are not adequately protected through legislation guided by scientific facts. The immediate consequences of which may include water-washed diseases, water-borne diseases and contamination of water leading to various health issues (Ajibade et al., 2015).

Judging from the above, the UNICEF and WHO (2019) reported that water is an essential service that must be provided in adequate quantity and quality for various reasons including health. The report declared that far too many children, women and men around the world die or get sick as a result of contaminated drinking water, many are being exposed to other people's excreta and many have no place to wash their hands. Also, mothers and newborns contract infection from unsanitary delivery room and many still defecate in the open due to lack of water and all these are risky to human health and well-being, a major reason why the 2030 agenda for Sustainable Development recognize safe drinking water, effective sanitation and good hygiene (WASH) both as an end in itself and as a driver of progress on many of the SDGs including health (UNICEF and WHO, 2019).

From the above review, children, women and the aged have been identified as more vulnerable to water problems especially during an outbreak of disease, the reason for the choice of a segment of them for this study. The Water Aid (2020) also asserted that the provision of safe water, sanitation and hygienic conditions is essential for protecting human health during all infectious disease outbreaks, including that of coronavirus disease (COVID-19). Ensuring evidenced-based and consistently applied WASH and waste management practices in communities, homes, schools, marketplaces, and health-care facilities will help prevent human-to-human transmission of the virus that causes COVID19.

The world is now in the midst of COVID-19, a global pandemic causing significant ill-health and death, and which to-date has no confirmed cure. This health crisis is again exposing the gaps and level of progress in national health systems and infrastructure provision all around the world. There is no country in the world that is untouched, however, the less developed country may bear more of the brunt if not properly managed. Weak water and sanitation systems can aggravate the COVID-19 crisis. The next section will attempt an overview of the COVID-19 disease and the essentiality of improved water connection to households and public facilities.

\subsection{Overview of the COVID-19 pandemic and the essentiality of adequate water connection to households and public facilities}

The novel coronavirus disease (COVID -19) was first traced to a wholesale food market in Wuhan City of China in December, 2019 and has rapidly spread to almost every region of the world (WHO, 2020a). The disease is caused by a new and severe type of coronavirus known as "severe acute respiratory syndrome - Corona Virus 2 (SARS-CoV 2)" (Balkhair, 2020). The disease, up till now has no known confirmed cure and was declared a worldwide pandemic causing morbidity and mortality 
by March, 2020 (WHO, 2020b). As at 10th August, 2020, there are 20,380,437 confirmed cases worldwide with sad occurrence of 743,013 deaths (Guardian Newspaper, 2020). Nigeria has also recorded about 47,157 confirmed cases with 955 deaths (NCDC, 2020).

COVID-19 as a viral infection is caused by a coronavirus that has not been previously identified in humans and this has brought a lot of complications towards discovery of vaccines for its treatment. Its outbreak and its potential speed of transmission require the need for proactive measures. According to the WHO (2020c), the disease spreads primarily from person to person through small droplets from the nose or mouth, which are expelled when a person with COVID-19 coughs, sneezes, or speaks. These droplets are relatively heavy, do not travel far and quickly sink to the ground. People can catch COVID-19 if they breathe in these droplets from a person infected with the virus. This is why it is important to stay at least 1 meter away from others. These droplets can land on objects and surfaces around the person such as tables, doorknobs and handrails. People can become infected by touching these objects or surfaces, then touching their eyes, nose or mouth (WHO, 2020c).

From the above, it can be deduced that hygiene has a very important role to play in the control of the spread of COVID-19. According to Nwobodo and Nwachukwu (2020), control of any form of disease largely depends on hygiene. Availability of clean water supply and soap for handwashing is one of the best ways to prevent the spread of infectious diseases, including COVID-19 (Water Aid, 2020). SWA (2020) informed that transmission of COVID-19 from person-to-person most commonly occurs through our hands and this risk is high when we touch a person who is infected or touch a surface that an infected person has touched. Thus, the syndrome - first action that we are therefore being told to practice to prevent ourselves from becoming infected, and to prevent us from infecting others, is to wash our hands generously with water and soap at all times.

The world at large now has to live with this new normal and promote hygiene especially at public spaces including schools if we must curb the spread of the dangerous virus and flatten the curve of COVID-19. In this time, especially while we still have neither cure nor vaccine, it is essential that we protect ourselves and others by washing our hands properly and maintaining good hygiene. This requires access to reliable and sufficient water and sanitation services, not only in the home, but critically, also in public places (Water Aid, 2020). Countries and regions need a sustainable water, sanitation and hygiene systems to protect the health of all and to save lives. According to the SWA (2020), the COVID-19 emergency is an opportunity to fast-track financing for WASH services critical for addressing health and other crises especially in low-income countries or areas that are currently under-served. Data from the Water Aid (2020) revealed that despite evidence of the effectiveness of good hygiene practices as the first line of defense in the prevention of infectious diseases, about 60 million people (32\%) in Nigeria lack access to basic water supply services and 150 million people (79\%) lack basic handwashing facilities with soap and water. Worse still, about 70,000 children under age 5 die every year from diseases caused by the nation's poor levels of access to clean water, decent toilets and good hygiene services. Furthermore, only $7 \%$ of schools and $5 \%$ of health facilities in the country have combined basic water, sanitation and hygiene (WASH) facilities.

The serious nations are currently on various responses to this crisis. This should however, be the reciprocated in all countries to avoid more serious crises and rise in the curve of the disease. This would depend on the actions, policies, institutions and capacity put in place by authorities and every stakeholder. The WHO (2020c) advised that governments must identify which specific groups in their country that are most at risk due to lack of water and sanitation services and ensure that they gain access immediately through removing barriers and extending services. Civil society organizations and other stakeholders including researchers have critical roles to play in assisting governments in their identification of marginalized and vulnerable individuals and groups, and how best to provide the appropriate support for these people. This study therefore falls in this category to contribute to the body of knowledge on the situation of improved water supply in our schools so as to determine the actions of the stakeholders in this sector towards adaptation to this new normal and evaluate their level of preparedness towards schools' resumption. 


\subsection{Methodology}

The study area selected for this research is Ijebu-North Local Government Area (LGA), one of the 20 LGAs in Ogun State, Nigeria. Ogun State within Nigeria context is located in the South-Western part of the country; bounded in the north by Oyo and Osun States, in the east by Ondo State, in the south by Lagos State and the Atlantic Ocean and in the west by the Republic of Benin. Ijebu-North, one of the biggest LGAs in Ogun State is surrounded by Ijebu North-East Local Government in the East, Odogbolu Local Government in the West and Oyo State in the North and South (see Figures 1 and 2). The LGA has towns like Ijebu-Igbo, Ago-Iwoye, Oru, Awa, Ilaporu and Mamu and numerous villages under its jurisdiction.

This study is designed to utilize both secondary and primary data to be considered for analysis and inferences. Thus, recent documents of UNICEF/WHO (2019) and Water Aid (2020) were utilized to gather data on water provision on premises and handwashing coverage. On the other hand, primary data on water availability, supply, connection to buildings, handwashing facility coverage and functionality were collected from public secondary schools in Ijebu-North LGA. According to reconnaissance survey, the LGA consists of 19 public secondary schools. These secondary schools constitute population for the study and $100 \%$ of these schools were used as sample size. Data collected were subjected to both descriptive and inferential analysis using percentage graphs and ChiSquare analysis respectively.

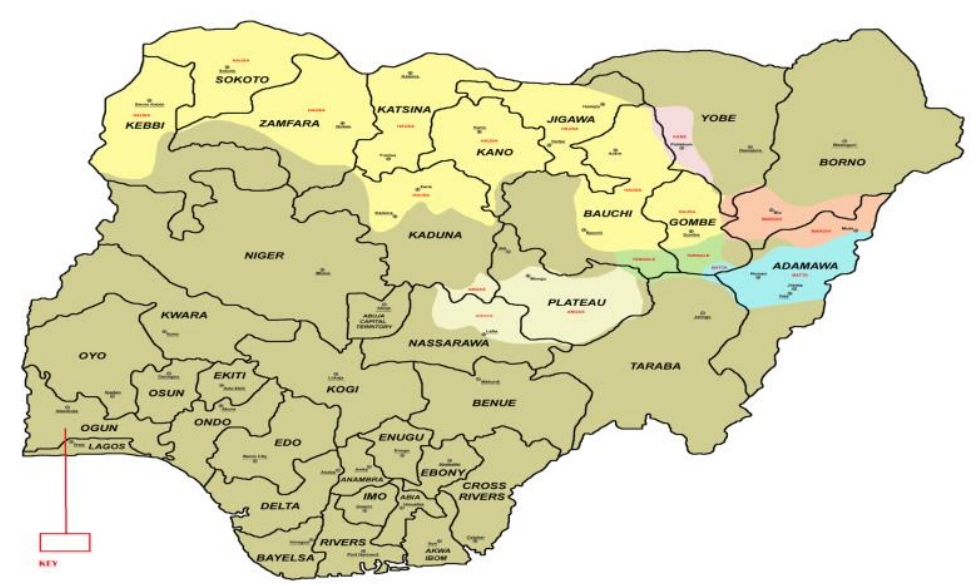

Figure 1: Ogun State within the context of Nigeria

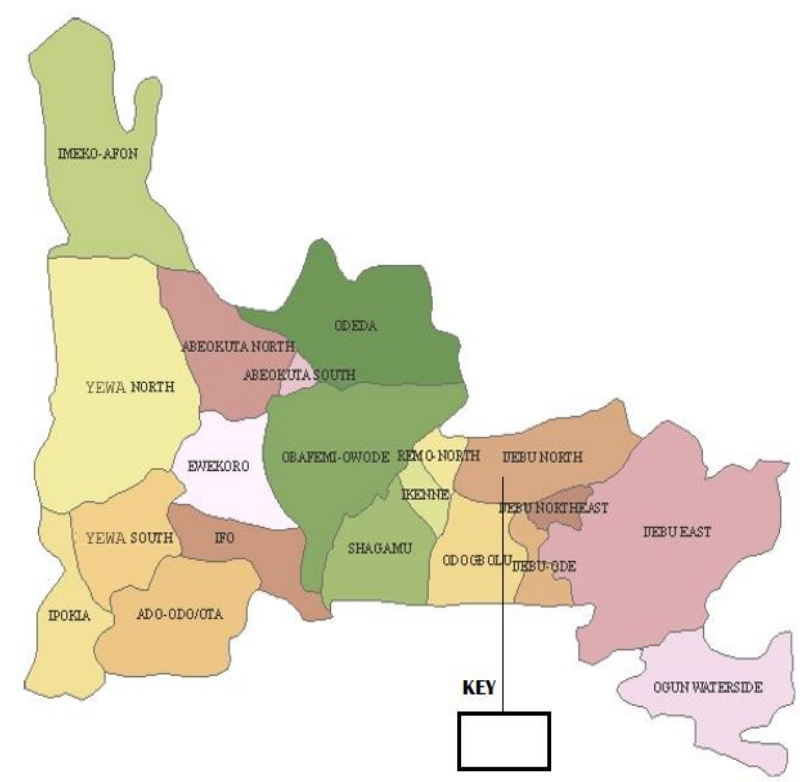

Figure 2: Ijebu North LGA within Ogun State 


\title{
3.0. Results and Discussions
}

\subsection{Running-water accessibility and handwashing facility}

Data contained in Figure 3 as sourced from the report of UNICEF and WHO (2019) informed that $75 \%$ of the world population can access water on their premises while $25 \%$ do not have access to water within their premises. Also contained in the Figure is the information that only $60 \%$ of the global population had basic handwashing facilities with soap and water available. While $22 \%$ had limited handwashing facilities, $18 \%$ do not have these facilities at all. This shows that while there is improvement in accessibility to water worldwide, handwashing and hygiene needs to step-up especially during this special period of COVID-19 crisis.

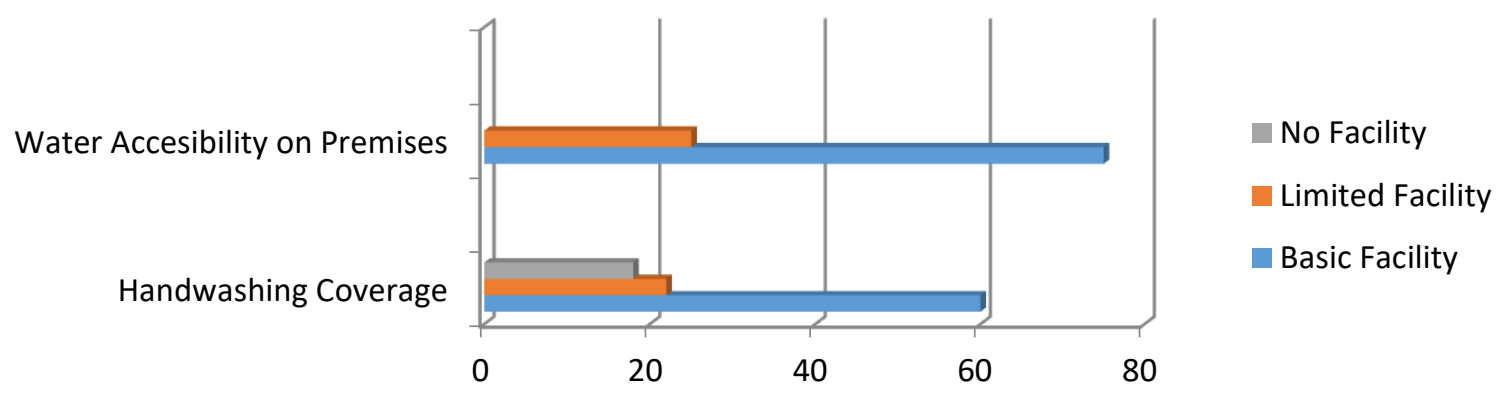

Figure 3: Global water accessibility on premises and handwashing coverage Source: UNICEF and WHO, 2019

\subsection{Least developed countries water accessibility on premises and handwashing coverage}

Secondary data reported in Figure 4 revealed that three quarter (75\%) of the population of the least developed countries had no access to water on their premises and nearly three quarter (73\%) also lacked handwashing facilities with soap and water. Less than $30 \%$, that is, $27 \%$ and $23 \%$ had no access to water within their premises and lack handwashing facility. This situation shows that many countries in the lower quintile may not be able to keep-up to the level of hygiene required to safeguard them from infectious diseases such as the COVID-19 pandemic.

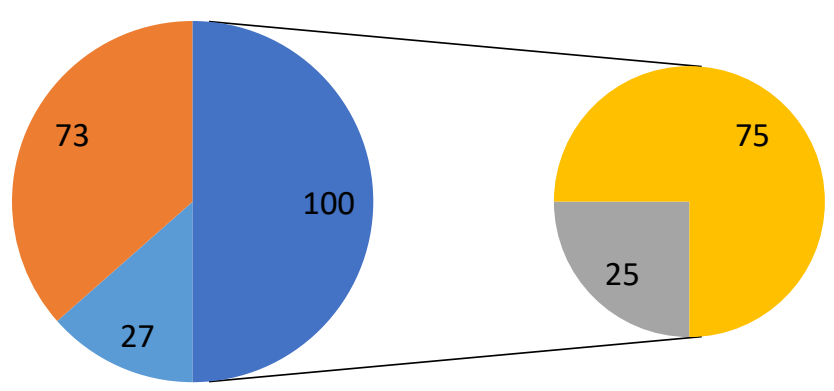

\author{
Water accessibility \\ No Water accesibility \\ Basic/Limited Handwashing \\ Facility \\ No Hanwashing Facility
}

Figure 4: Water accessibility in premises and handwashing coverage in least developed countries Source: UNICEF and WHO, 2019

\subsection{Water accessibility on premises and handwashing coverage in Nigeria}

Figure 5 compiled data from the report of both UNICEF/WHO (2019) and Water Aid (2020) on water accessibility on premises and handwashing coverage as obtained in Nigeria. The Figure revealed that $70 \%$ of the population does not have access to water within their premises and $75 \%$ lack basic handwashing facility at home. These statistics may be an indication that government and other stakeholders in water, sanitation and hygiene are not enough to close the need gap. This will no doubt affect the level at which the country will mitigate the community spread of COVID-19 and flatten its curve. 


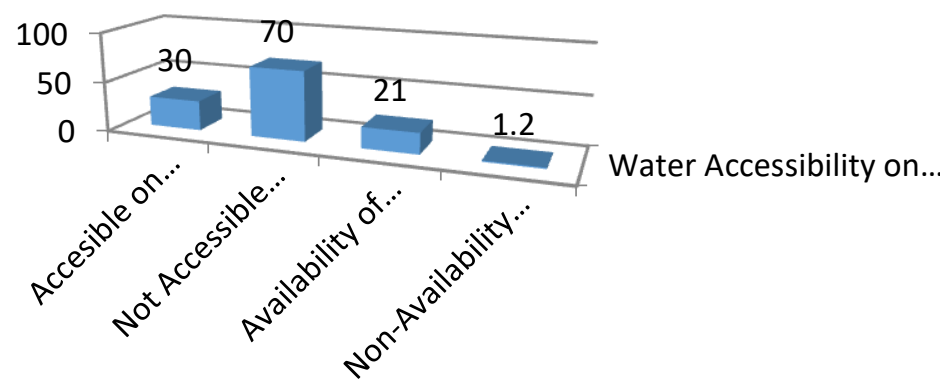

Water Accessibility on Premises and Handwashing

Figure 5: Water accessibility in premises and handwashing coverage in Nigeria Source: UNICEF and WHO (2019) and Water Aid (2020)

\subsection{Availability and functionality of running-water and handwashing facility in Secondary Schools of the study area}

The matrix on Table 1 revealed the primary data collected from all secondary schools of Ijebu-North Local Government Area of Ogun State, Nigeria; the area selected for this study. The Table revealed that only one school (Molusi College, Ijebu-Igbo) is fully equipped with running water connected to buildings and with functional handwashing facilities in place. Data derived from the study area showed that most of these schools do not have water infrastructure that can support adequate hygiene as the matrix showed a score of 16 out of the total score of 95 . This is an indication that the secondary schools in the study area are not in a position to tackle infectious disease through hygiene. Figure 6 revealed the situation in pictures.

Table 1: Matrix for availability and functionality of running-water and handwashing facility in Secondary Schools of Ijebu-North LGA, Ogun State Nigeria

\begin{tabular}{lllllll}
\hline Secondary schools & \multicolumn{5}{c}{ Water data } \\
\cline { 2 - 7 } & ARW & CWS & WCB & AHF & FHF & Total \\
\hline Ahmadiyya High School Ago-Iwoye & - & - & - & - & - & 0 \\
Ago-Iwoye Secondary School & + & - & - & - & - & 1 \\
Fowoseje Comprehensive High School Ago-Iwoye & - & - & - & - & - & 0 \\
Abobi Comprehensive High School Ago-Iwoye & - & - & - & - & - & 0 \\
Muslim High School ago-Iwoye & - & - & - & - & - & 0 \\
Methodist High School Ago-Iwoye & + & - & - & - & - & 1 \\
Mamu Comprehensive High School Mamu-Ijebu & - & - & - & - & - & 0 \\
Obanta Comprehensive High school Awa-Ijebu & - & - & - & - & - & 0 \\
Itamerin Comprehensive High School Oru-Ijebu & + & - & - & - & - & 1 \\
Abusi-Edumare Academy Ijebu-Igbo & + & - & + & + & - & 3 \\
Ijebu-Igbo Girls Grammar School & + & - & + & - & - & 2 \\
Olokine Comprehensive High School Ijebu-Igbo & - & - & - & - & - & 0 \\
Kegbo Comprehensive High School Ijebu-Igbo & + & - & - & - & - & 1 \\
Sopin Comprehensive High School Ijebu-Igbo & - & - & - & - & - & 0 \\
Molusi College Ijebu-Igbo & + & + & + & + & + & 5 \\
Beje High School Ijebu-Igbo & + & - & - & - & - & 1 \\
Shamsudeen College Ijebu-Igbo & + & - & - & - & - & 1 \\
Ladugbo Community High school Ijebu-Igbo & - & - & - & - & - & 0 \\
Japara High School Ijebu-Igbo & - & - & - & - & - & 0 \\
\hline Total & 9 & 1 & 3 & 2 & 1 & $16 / 95$
\end{tabular}

KEY: AWS- Availability of Water Supply; CWS- Constant Water Supply; WCB- Water Connection to Buildings; AHFAvailability of Handwashing Facility; FHF- Functional Handwashing Facility.

Source: Author's Field Survey, 2020 


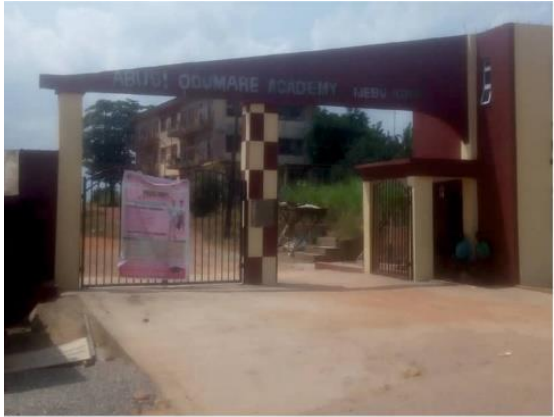

\section{ABUSI EDUMARE ACADEMY IJEBU-IGBO}
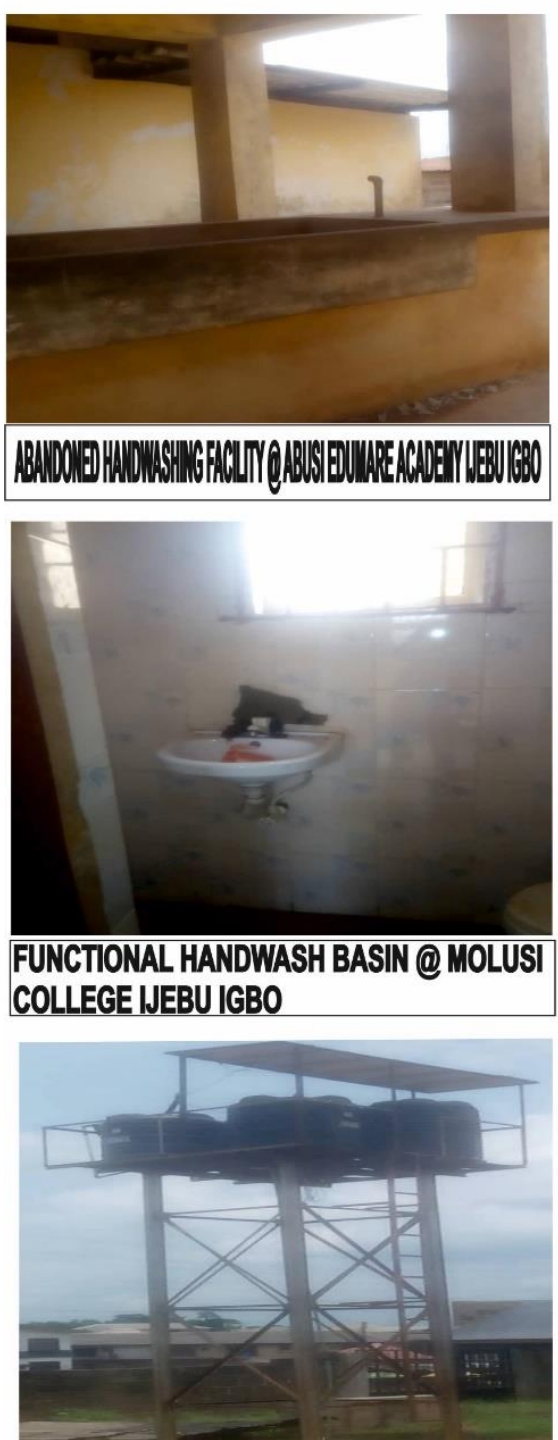

DYSFUNCTIONAL SOLARBOREHOLE FACILTYY Q TTANERIN COMPREHENSIVE HIGH SCHOOL ORUAJEBU

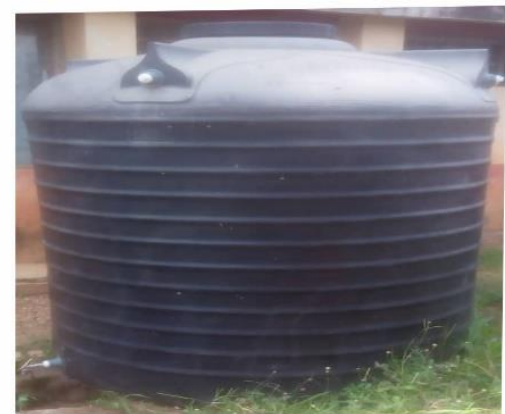

TANKFORSTORAGEOF RANWATER@ABUSIEDUMARE ACADEMYIJEBUIGBO
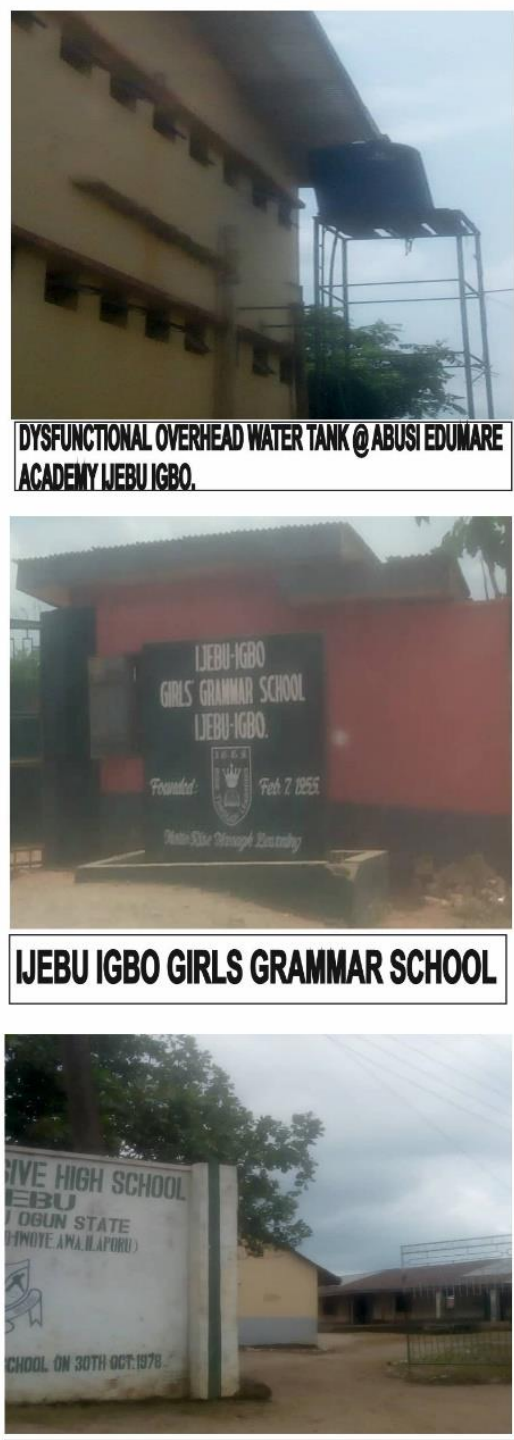

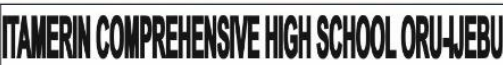

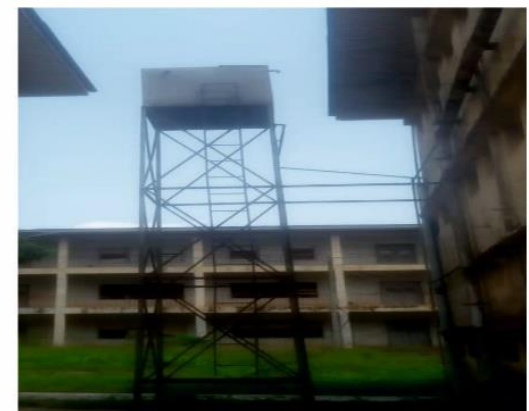

ABANDONED WATERRESERVOR@ABUSIEDUWARE ACADEMYINEBUIGBO

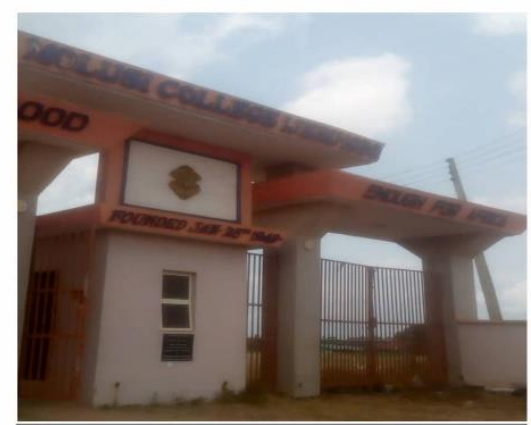

MOLUSI COLLEGE IJEBU IGBO
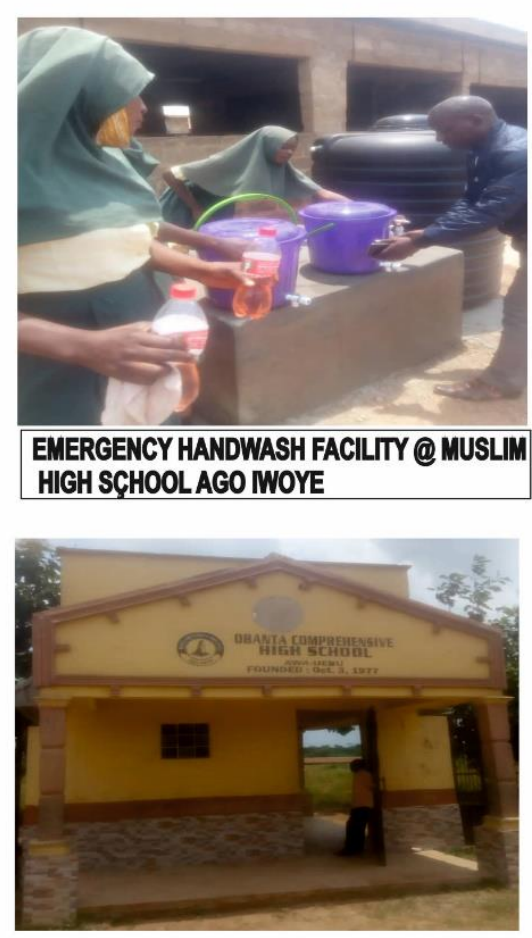

OBATA CONPPEHENSNEHIIGH SCHOOLANAAJEBU

Figure 6: Pictures showing water situation in Secondary Schools of the study area Source: Authors' Field Work, 2020

Field study as contained in Table 1 revealed that where water infrastructures were initially provided, they are presently in states of disrepair and not functioning. The result above confirmed the earlier statistics of the Water Aid (2020) and UNICEF/WHO (2019) that less developed countries have not met up with the water, sanitation and hygiene expectations despite progress recorded in worldwide. 


\subsection{Chi-Square test}

The chi-square goodness-of-fit test is a nonparametric test otherwise known as the one-sample goodness-of-fit test. It is used to determine whether the distribution of cases (e.g. schools) in a single categorical variable (e.g. "responses", consisting of two groups: "No" and "Yes") follows a known or hypothesized distribution. In addition, the result of the analyses presented in Tables $2,3,4,5, \& 6$ indicates the observed frequencies (Observed $\mathbf{N}$ ) and its proportion (Observed \%) for each water data, and the expected frequencies (Expected N) and the actual result of the chi-square goodness-offit test.

The result in Table 2 provides the result of the chi-square goodness-of-fit test in which the availability of water supply (tap) varied as a function of group size. It revealed that the secondary schools in Ijebu-North Local Government Area of Ogun state that have the provision/availability of water supply (i.e. tap water) were slightly more, compare to those schools (i.e. 8 schools) that do not have tap water supply.

Also, we can see from this table that our test statistic is not statistically significant: $\chi^{2}(1)=0.474, p$ > 0.05 . Therefore, we fail to reject the null hypothesis that the observed proportions are significantly different from the specified proportions. The percentage was 58\% to $42 \%$ respectively which implies that $58 \%$ of the selected schools in the study area actually have water provided initially within their premises.

Table 2: Availability of water supply (tap)

\begin{tabular}{llll}
\hline & Observed N & Observed \% & Expected N \\
\cline { 2 - 4 } Yes & 11 & 57.9 & 9.5 \\
No & 8 & 42.1 & 9.5 \\
Total & 19 & 100.0 & \\
Chi-Square $=.474 ; d f=1, P=.491$ & \\
\hline \multicolumn{5}{r}{ Source: } & Researchers' Computation from SPSS 25
\end{tabular}

The result in Table 3 revealed that the secondary schools in the study area that have constant water supply were relatively low compare to those schools (i.e. 18 schools) that do not have constant water supply. Also, we can see from this table that our test statistic is statistically significant: $\chi^{2}(1, N=19)=$ $15.211, p<0.05$. Therefore, we reject the null hypothesis and conclude that the observed proportions are significantly different from the specified proportions. The percentage was 5\% compare to $95 \%$ respectively which implies that only 5\% of the selected schools in the study area can stand the test of hygiene and actually ready to combat the spread of COVID-19 through constant water availability.

Table 3: Constant water supply

\begin{tabular}{llll}
\hline & Observed N & Observed \% & Expected N \\
\cline { 2 - 4 } Yes & 1 & 5.3 & 9.5 \\
No & 18 & 94.7 & 9.5 \\
Total & 19 & 100.0 & \\
Chi-Square $=$ & $15.211, d f=1, P=.000$ \\
\hline \multicolumn{5}{r}{ Source: } & Researchers' Computation from SPSS 25
\end{tabular}

The result in Table 4 shows that the secondary schools in the study area that have water connected to the school buildings were low compare to others (i.e. 16 schools) that do not have. Also, we can see from this table that our test statistic is statistically significant: $\chi^{2}(1, N=19)=8.895, p<0.05$. Therefore, we reject the null hypothesis and conclude that the observed proportions are significantly different from the specified proportions. The percentage was 16\% compare to $84 \%$ respectively which implies that only $16 \%$ of the selected schools were fully provided with water connections to keep-up with hygiene when schools resume. 
Table 4: Water to buildings

\begin{tabular}{llll}
\hline & Observed N & Observed \% & Expected N \\
\cline { 2 - 4 } Yes & 3 & 15.8 & 9.5 \\
No & 16 & 84.2 & 9.5 \\
Total & 19 & 100.0 & \\
Chi-Square $=8.895, d f=1, P=.003$ & \\
\hline \multicolumn{5}{r}{ Source: } & Researchers' Computation from SPSS 25
\end{tabular}

The result in Table 5 revealed that the secondary schools in Ijebu-North Local Government Area of Ogun state that have handwashing facilities available in buildings were relatively low compare to those schools (i.e. 17 schools) that do not have it. Also, we can see from this table that our test statistic is statistically significant: $\chi^{2}(1, N=19)=11.842, p<0.05$. Therefore, we reject the null hypothesis and conclude that the observed proportions are significantly different from the specified proportions. The percentage was $11 \%$ compare to $89 \%$ respectively which implies that only $11 \%$ of the selected schools in the study area can fully boast that they can comply with the COVID-19 guideline of handwashing facility as the government stipulated before they can open.

Table 5: Availability of hand washing facilities

\begin{tabular}{llll}
\hline & Observed N & Observed \% & Expected N \\
\cline { 2 - 4 } Yes & 2 & 10.5 & 9.5 \\
No & 17 & 89.5 & 9.5 \\
Total & 19 & 100.0 & \\
Chi-Square $=$ & 11.842, $d f=1, P=.001$ \\
\hline \multicolumn{5}{r}{ Source: } & Researchers' Computation from SPSS 25
\end{tabular}

The result in Table 6 revealed that the secondary schools in the study area that have the handwashing facilities in a functional state were relatively low compare to those schools (i.e. 18 schools) that do not have it. Also, we can see from this table that our test statistic is statistically significant: $\chi^{2}(1, N=19)=$ $15.211, p<0.05$. Therefore, we reject the null hypothesis and conclude that the observed proportions are significantly different from the specified proportions. The percentage was 5\% compare to $95 \%$ respectively which implies that only $\mathbf{5 \%}$ of the selected schools in the study area can comply fully with the COVID-19 handwashing guideline as stipulated by the government if nothing serious is done before schools' resumption.

Table 6: Functionality of hand washing facilities

\begin{tabular}{llll}
\hline & Observed N & Observed \% & Expected N \\
\cline { 2 - 4 } Yes & 1 & 5.3 & 9.5 \\
No & 18 & 94.7 & 9.5 \\
Total & 19 & 100.0 & \\
Chi-Square $=15.211, d f=1, P=.000$ \\
\hline \multicolumn{5}{r}{ Source: } & Researchers' Computation from SPSS 25
\end{tabular}

\subsection{Conclusions}

The WHO (2020) informed that regular and thorough washing of hands with soap and water reduces the chances of being infected by or spreading COVID-19. Soap and water kill viruses that may be on your hands. If you have clean hands, there is less chance you can transfer the virus to your eyes, nose or mouth when you touch your face. Also, if the virus gets into your hands and you do not wash them, it can be transferred to other people and objects, like handrails, table tops, or toys, and then transferred to another person's hands. Thus, adequate water is required to halt the spread of the deadly virus. Meanwhile, as efforts are going on by individuals and stakeholders in the WASH sector to provide water for homes, this study revealed that reverse is the case in the public secondary schools of the study area. This is counter-productive to the fight against COVID-19. It is also safe to conclude that many of this educational facility are unsafe in this period and not prepared for the much-anticipated resumption after about five months of their lockdown. This is also an indication that our country and her major stakeholders are either not having the will to do the necessary or may not have learnt from the past and see water as an essential service that must be provided to ensure individual and community health for all and sundry. 
This study therefore wants to make case for the prioritization of water in schools. It is usually an eyesore to see students defecating in the open in schools or leave the school premises before the closing hour as results of lack of water within the school. These may take toll on community health especially at times like this if students are allowed to resume schools. Government and other donors should therefore as a matter of emergency facilitate investments in water, sanitation and hygiene in order to prepare these schools for resumption and sustain this after this health crisis. Part of the COVID-19 funds and Constituency projects of politicians should be channeled this time to this allimportant infrastructure if we are truly serious about school's resumption.

While it can be acknowledged that various levels of government and other stakeholders have started providing emergency water storage facilities and make-shift bucket taps for handwashing to be managed by the schools. Observations revealed that these are not sustainable as water contained in them is not enough for proper hygiene. Thus, a special water and hygiene task-force is recommended to be put in place to visit schools and present a quick report about the situation of each school based on their peculiarity. This will bring to the knowledge of the government and the public the water needs of the school which ordinarily may not be known to the stakeholders before now.

Lastly, maintenance culture is usually lacking in most of our public institutions, schools inclusive. Observations in some of the schools investigated showed that there were recent interventions towards improved water provision by donors. Sadly, these infrastructures are now in states of disrepair. This study advocates for direct taking over of any water infrastructure provided in schools by the Water Agency in the areas where these schools are allocated. This take-over will be for the purpose of routine maintenance for the sustainability of the water infrastructure and thus preparedness for any water needs for the current and any future crisis.

\section{References}

Ajibade, F. O., Adewunmi, J. R., Ojo, O. M., Babatola, J. O. and Oguntuase, A. M. (2015). Issues, Challenges and Management of Water Supply in Nigeria: An Overview. Proceedings of the 2015 Conference of the Nigerian Institute of Civil Engineers, October, 2015.

Balkhair, A. A. (2020). COVID-19 Pandemic: A New Chapter in the History of Infectious Diseases. Oman Medical Journal, 35(2), p. e123.

Flanagan, S. V., Johnson, R. B. and Zheng, Y. (2012). Arsenic in Tube Well Water in Bangladesh: Health and Economic Impacts and Implications for Arsenic Mitigation. Built World Health Organization, 90, pp. 839-846.

NCDC (2020). COVID-19: Guidance for Schools in Nigeria. VERSION 1. NCDC, Abuja Nigeria

Nwobodo, T. N. and Nwachukwu, K. E. (2020). COVID-19 Era and Water Supply: Challenges for Rural Communities in Eastern Nigeria. Journal of Geoscience and Environment Protection, 2020(8), pp. 219-233.

Olajuyigbe, A. E. and Fasakin, J. O. (2010). Citizens Willingness to Pay for Improved Sustainable Water Supply in a Medium-Sized City in South Western Nigeria. Current Research Journal of Social Sciences, 2(2), pp. 41-50.

Owens, J. (2020). Retrieved from https://www.livescience.com/worst-epidemics-and-pandemics-inhistory.html (Accessed at: 26/04/2020)

Pascale, H. (2009). Access to Water Supply and Sanitation Services (WSS) of Low-Income Households in the Peri-Urban Interface of Developing Countries. Development Planning Unit, University College, London.

Sanitation and Water for All- SWA (2020). COVID-19 and Water, Sanitation and Hygiene: Message for Policy Makers. 
Tornqvist, R. (2007). Planning Support for Water Supply and Sanitation in Peri-Urban Areas. A Master's Thesis Submitted to the Department of Information Technology, Uppsala University, Sweden.

UN (2002). Facts about Water. Fact Sheet, Johannesburg Summit 2002. Johannesburg, South Africa. Retrieved from www.un.org/jsummit/html/media_info/

UNDP (2006). Human Development Report 2006: Beyond Scarcity: Power, Poverty and the Global Water Crisis. Palgrave Macmillan, New York: 442.

UNEP (2002). GEO 3 at a Glance: Fresh Water. Our Plannet, 3(2): 18

UNICEF and WHO (2019). Progress on Household Drinking Water, Sanitation and Hygiene-20002017: Special Focus on Inequality. New York: UNICEF and WHO.

Water Aid (2020). Halting the Spread of COVID-19 and other Infectious Diseases in Nigeria through Universal Access to Water, Sanitation and Good Hygiene. file:///C:/Users/Test/Desktop/wateraidnigeria-covid-19-situational-map-_-updated-june- 11-2020_0\%20(1).pdf

WHO (2012). Cholera 2011. Weekly Epidemiological Report and Transactions of the Royal Society of Tropical Medicine and Hygiene, 81, pp. 51-55.

WHO and UNICEF (2004). Joint Monitoring Programme for Water Supply and Sanitation; Meeting the MDGs Drinking Water and Sanitation Target: A Mid-Term Assessment of Progress, WHO, Geneva.

World Health Organization (2020a). Disease Outbreak by Year.

World Health Organization (2020b). Coronavirus Disease 2019 (COVID-19) Situation Report- 94.

World Health Organization (2020c). Save Lives: Clean your Hands. https:www.who.int/infection.prevention/campaign/clean-hands/en. Accessed Monday 4th August, 2020.

Cite this article as:

Olajuyigbe A. O., Okubena M. R., Rotowa O. O. and Ayodele O. A. 2021. COVID-19 Pandemic and Hygiene: Assessment of Running-water Infrastructure in Secondary Schools in Ijebu North Local Government Area, Ogun State, Nigeria. Nigerian Journal of Environmental Sciences and Technology, 5(2), pp. 523-534. https://doi.org/10.36263/nijest.2021.02.0296 